Original Research Paper

\title{
Utilization of Home Yard for Lettuce Cultivation with a Hydroponic
}

\author{
Ungki Marnando $^{1 *}$, Widayanti ${ }^{1}$, Septilia $^{1}$, Uswatun Hasanah $^{1}$ \& Arini Rosa Sinensis ${ }^{1}$ \\ ${ }^{1}$ Physics Education, STKIP Nurul Huda, Palembang, Indonesia;
}

\author{
Article History \\ Received : December 04 $4^{\text {th }}, 2021$ \\ Revised : December $13^{\text {th }}, 2021$ \\ Accepted : December $20^{\text {th }}, 2021$ \\ Published : January $05^{\text {th }}, 2022$ \\ *Corresponding Author: \\ Ungki Marnando, \\ Pendidikan Fisika, Palembang, \\ Indonesia \\ Email: \\ ungkimarnando5@gmail.com
}

\begin{abstract}
The development of technology is currently very rapid, especially technological developments in the agricultural sector. However, some farmers do not use the land as an agricultural business. The purpose of the study was to provide a strategy for using yard land as hydroponic lettuce cultivation. This research method is a survey. The research instrument used an open questionnaire, interviews and analyzed descriptively qualitatively. The results showed that vegetable cultivation can be done hydroponically. Vegetables grown hydroponically in this study were lettuce. Planting using a hydroponic system is an environmentally friendly plant process because its cultivation does not require excessive pesticides. In addition, it can take advantage of a narrow land as a planting medium. Further research needs to analyze the types of hydroponic plants that are suitable for each surrounding area
\end{abstract}

Keywords: Narrow Land, Hydroponic System, Lettuce

\section{Pendahuluan}

Pertanian merupakan suatu hal yang sangat penting bagi masyarakat. Pertanian merupakan sumber penghasilan utama bagi masyarakat, karena sebagian besar sumber penghasilan masyarakat Indonesia berasal dari pertanian. Tanah biasanya digunakan petani untuk media pertanian. Media tersebut sudah menjadi hal umum yang digunakan dalam pertanian. Banyaknya lahan pertanian yang tidak dikelola oleh masyarakat, untuk memanfaatkan lahan pertanian tersebut guna meningkatkan hasil pertanian,yaitu sistem tanam dengan hidroponik (Roidah, 2014). Hidroponik merupakan lahan pertanian yang tidak menggunakan media tanah, sehingga hidroponik merupakan salah satu aktivitas pertanian dengan menggunakan media air pengganti tanah. Sayuran yang umumnya ditanam menggunakan media hidroponik yaitu tomat, bayam, selada, kangkung, seledri, dan sebagainya (Romalasari \& Sobari, 2019). Menanam sayuran menggunakan cara hidroponik merupakan salah satu cara yang bisa dikatakan ramah lingkungan, dikarenakan media tanamnya tidak menggunakan pestisida secara berlebihan (Warjoto et al., 2020).

Hidroponik sendiri tidak banyak memakan lahan. Pengembangan pertanian dapat menggunakan air sebagai penggganti tanah. Sehingga budidaya menggunakan sistem hidroponik dapat menjadi suatu inisiatif dalam memanfaatkan lahan pekarangan yang sempit (Paramita \& Yuliani, 2021). Budidaya dengan sistem hidroponik lebih mempermudah untuk mengontrol pertumbuhan dalam tanaman dalam lingkungan. Lahan yang luas tidak diperlukan dalam budidaya dengan sistem hidroponik dan budidaya dengan sistem hidroponik tidak mengenal musim. Ada beberapa media tanam yang dapat digunakan dalam budidaya dengan sistem hidroponik, media tanam yang sering digunakan yaitu rockwool (Lathifah et al., 2021; Paramita \& Yuliani, 2021). Rockwool memiliki kemampuan dapat lebih banyak menahan air dan udara dalam jumlah besar oleh karena itu rockwool sangat disarankan untuk digunakan sebagai media tanam.

Metode hidroponik adalah media yang dapat digunakan untuk proses pertumbuhan tanaman. Media tersebut bebas dari unsur hara (steril) (Fatmawati et al., 2021). Sementara itu pemberian ubsur hara yang diperlukan tanaman dialihkan menggunakan pipa sebagai medianya atau bisa juga disiramkan langsung. Media tanam hidroponik bisa berupa gabus, pasir, batu kecil, 
ceropong/arang atau bisa juga tanpa media material granular (Fajri et al., 2021). Dalam media tanam hidroponik yang paling penting harus bersih dari serangga agar tidak menimbulkan berbagai penyakit atau jamur supaya tanaman tidak rusak (Asri et al., 2021). Dengan seiringnya perkembangan jumlah penduduk, semakin meningkat juga kebutuhan pangan bagi masyarakat seperti sayuran dan buah-buahan. Sehingga tidak disamakan dengan pertumbuhan dilahan pertanian yang kebetulan lebih sempit. Dikota-kota besar lingkup sentra pertaniannya beralih fungsi menjadi lahan karena permukimannya tidak dapat tempat lagi. Sementara itu, model usaha pertanian yang paling tepat yaitu dengan sistem hidroponik, sebagai salah satu solusi untuk mengatasi masalah pangan. Sistem pertanian hidroponik bisa menanam berbagai jenis tanaman, namun masyarakat banyak memilih menanam tanaman semusim.

Sistem hidroponik diterapkan karena dapat menjadikan lingkungan lebih tertata dan dengan pengembangan teknologi, yang berpaduan sistem hidroponik dengan membran yang mampu memanfaatkan air nutrisi dan pestisida secara nyata dan lebih mudah. Dibanding dengan kultur tanah (yang paling penting untuk tanaman berumur singkat). Sistem hidroponik tidak perlu menggunakan lahan yang luas dan tidak mengenal musim di bandingan dengan kultur tanah untuk mendapatkan produk yang sama (Romalasari \& Sobari, 2019). Dalam budidaya dengan sistem hidroponik nutrisi yang digunakan yaitu nutrisi $\mathrm{A}$ dan nutrisi $\mathrm{B}$ ataupun campuran nutrisi A dan B. Biasanya di toko khusus Hidroponik kita bisa mendapatkan Nutrisi ini sudah siap digunakan.

Tabel 1. Kandungan Nutrisi A dan Nutrisi B

\begin{tabular}{|c|c|}
\hline \multicolumn{2}{|c|}{ Kandungan Nutrisi } \\
\hline Nutrisi A & Nutrisi B \\
\hline $\begin{array}{l}\text { Kalsium amonium } \\
\text { nitrat }\end{array}$ & $\begin{array}{l}\text { Kalium dihidro } \\
\text { sulfat }\end{array}$ \\
\hline Kalium nitrat & Amonium sulfat \\
\hline Fe-EDTA & Magnesium sulfat \\
\hline \multirow[t]{5}{*}{$\mathrm{Fe}$} & Mangan sulfat \\
\hline & Tembaga sulfat \\
\hline & Seng sulfat \\
\hline & Asam borat \\
\hline & Amonium molibdat \\
\hline
\end{tabular}

Sayuran merupakan salah satu bahan pangan yang sangat dibutuhkan oleh tubuh manusia. Oleh karena itu banyak sumber nutrisi yang terkandung dalam sayuran, baik itu potasium, serat makanan, asam folat, vitamin A dan vitamin C. Tanaman jenis selada juga banyak dibudidayakan secara hidroponik. Selada (Lactuca sativa L) merupakan sayuran yang mempunyai potensi besar untuk dikembangkan sebagai usaha agribisnis. Selada adalah jenis tanaman yang tidak hanya tumbuh didaerah dingin tetapi juga di tropis. Semakin bertambahnya penduduk di Indonesia dan meningkatnya kesadaran penduduk akan kebutuhan gizi mengakibatkan meningkatnya permintaan akan sayuran. Kandungan gizi yang ada pada sayuran terutama vitamin dan mineral tidak dapat digantikan oleh makanan pokok.

\section{Bahan dan Metode}

Penelitian ini menggunakan media tanam rockwool, dan Penelitian ini dilaksanakan selama satu minggu sekali yakni dihari jumat di kediaman Saudara Jaya Herianto Simarmata di Desa Jatimulyo I, kecamatan Belitang Madang Raya, selama 1 bulan 28 hari. Teknik pengambilan sampling dilakukan secara random dan diamati secara konsisten dengan objek yang sama setiap pengamatan. Instumen penelitian berupa angket sistematis sesuai indikator perkembangan tumbuhan hidroponik. Data dianalisis secara deskriptif kualitatif. Adapun tahap penelitian ditunjukkan pada alur berikut.

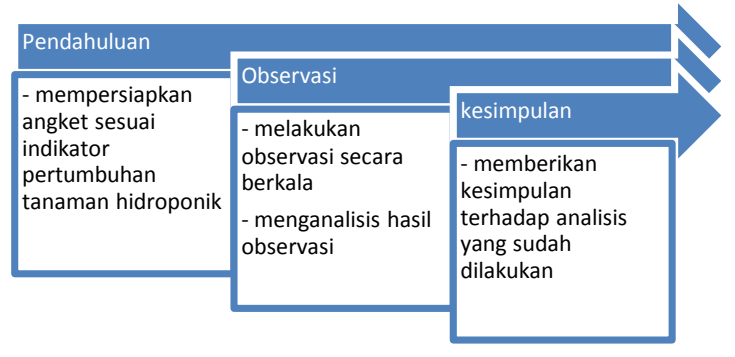

Gambar 1. Alur Penelitian

\section{Hasil dan Pembahasan}

\section{Pengertian Hidroponik}

Hidroponik berasal dari kata Yunani yaitu hydro yang berarti air dan ponos yang artinya pengerjaan atau bercocok tanam. Hidroponik 
juga dikenal sebagai Soilless Culture atau menanam tanaman tidak menggunakan tanah tetapi menggunakan media lain seperti pasir, kerikil, air, dan material lainnya. Menanam tanaman dengan cara hidroponik mempunyai keuntungan antara lain tanaman yang diproduksi lebih berkualitas, tanaman dikontrol, tanaman jarang terserang hama penyakit (Sanubary et al., 2021). Kebutuhan tanaman dapat disesuaikan dengan pemberian larutan unsur hara lebih efektif dan efisien, dapat diusahakan karena tidak bergantung pada musim dan lahan sempit.

Secara umum nutrisi hidroponik menggunakan nutrisi $\mathrm{A}$ dan $\mathrm{B}$ ataupun bisa dicampur antara nutrisi $\mathrm{A}$ dan $\mathrm{B}$, nutrisi bisa didapatkan di toko khusus hidroponik. Nutrisi A terdapat kandungan seperti kalium nitrat, dan FeEDTA, serta Fe, kalsium aminonium nitrat, sedangkan nutrisi $\mathrm{B}$ terdapatat kandungan amonium sulfat, mangan sulfat, kalium dihidrosulfat, magnesium sulfat, seng sulfat, tembaga sulfat, amonium moliptad dan asam borat (Kusumo \& Azis, 2021; Masitah et al., 2021).

\section{Hidroponik tanaman selada}

Ribuan tahun lalu orang mesir pertama kali membudidayakan selada (Lactuca sativa L). Biji selada digunakan orang mesir untuk menghasilkan minyak dan juga memanfaatkan daun sayuran selada ini. Banyak kandungan dalam selada yaitu banyak kandungan air, energy yang sedikit, lemak, protein, karbohidrat, gula dan serat makanan (Ramady et al., 2021). Dalam selada juga terdapat banyak mineral dan vitamin yaitu zat besi, kalsium, fosfor, magnesium, kalium, seng dan natrium bersama dengan vitamin B seperti riboflavin, thiamin, niasin, vitamin $\mathrm{B} 6$, folat, dan vitamin $\mathrm{C}, \mathrm{A}, \mathrm{E}$, dan $\mathrm{K}$. Karena kandungan nutrisi dalam selada sangat banyak, tentunya selada juga banyak mengandung khasiat terutama dalam Kesehatan (Primawati et al., 2021).

\section{Manfaat hidroponik}

a. Termasuk tanaman bebas hama, sebab jika menggunakan tanah terkadang hama muncul dari dalam tanah itu sendiri. Sistem hidroponik baik digunakan untuk bercocok tanam karena bisa menghindari hama yang menjadi musuh utama tanaman. b. Hasil yang didapat lebih banyak karena tanaman tidak terlalu banyak dimakan hama dan tidak terbuang sia-sia.

c. Lebih sehat, karena tanaman hidroponik tidak menggunakan bahan kimia atau pestisida. Karena dalam hidroponik menggunakan medium utama air maka jarang atau bahkan tidak ada hama sama sekali.

d. Bisa panen kapan saja. Dalam sistem hidroponik sangat memungkinkan untuk memanen kapan saja sesuai keinginan. Sekalipun bukan musim tanaman tersebut.

\section{Keunggulan dan kelemahan hidroponik}

Kelebihan sistem hidroponik yaitu : penggunaan lahan tanaman berproduksi tidak menggunakan tanah kuantitas dan kualitas produksinya lebih bersih dan lebih tinggi dalam penggunaan air dan pupuk lebih efisien pengendalian penyakit dan hama yang lebih mudah (Haryanto et al., 2021; Romalasari \& Sobari, 2019). Kekurangan sistem hidroponik yaitu: dibutuhkan modal yang sangat besar ada kultur substrat, kapasitas air dalam media substrat lebih rendah daripada media tanah sehingga dapat menyebabkan pada tanaman yang cepat layu.

\section{Cara menanam selada hidroponik}

Tahap penyemaian benih. Media tanam yang digunakan yaitu rockwool. Masing-masing media tanam dipotong dengan ukuran $2,5 \mathrm{~cm} \mathrm{x}$ $2,5 \mathrm{~cm} \times 2,5 \mathrm{~cm}$ dan direndam dalam air hingga basah. Setelah dibasahi rockwool dilubangi dengan menggunakan tusuk gigi untuk tempat biji selada yang akan ditanam. Benih selada diletakkan pada masing-masing media tanam yang sudah dilubangi menggunakan tusuk gigi. Kelembapan media tanam dijaga agar proses perkecambahan dapat berlangsung dengan baik. Setelah biji ditanam tunggu hingga 2 hari ditempat yang lembab sampai berkecambah. Dan setelah 2 hari bibit sudah bisa diletakkan di tempat yang terkena sinar matahari agar tidak terjadi KUTILANG (kurus tinggi langsing) atau dalam Bahasa ilmiah disebut Etiolasi.

Tahap penyinaran cahaya matahari. Tahap ini mengamati perkembangan biji selada setelah 3 hari dan telah mengalami perkecambahan. Perkembangan biji yang 
berkecambah yaitu tumbuhnya 2 daun yang disebut daun sejati, dan tinggi kecambah sekitaran $1,5-2 \mathrm{~cm}$. Dalam tahap ini bibit mulai di letakkan di luar ruangan supaya terkena sinar matahari selama 3 hari, setelah 3 hari baru bias dipindahkan ke tahap peremajaan dan akan tumbuh daun baru.

Tahap peremajaan. Biji yang telah 3 hari mendapat penyinaran cahaya matahari sudah mulai bisa dipindahkan ke tempat peremajaan. Saat diperemajaan daun sudah terdapat 3 daun yang tumbuh, dalam peremajaan nutrisi yang digunakan berkisaran 300-400 PPM. Bibit selada kurang lebih 1 minggu dalam tahap peremajaan, setelah 1 minggu dalam tahap peremajaan selada dipindahkan ke tahap pembesaran.

Tahap pembesaran. Setelah kurang lebih 1 minggu dalam peremajaan bibit selada sudah dapat dipindahkan dalam tahap pembesaran. Dalam tahap ini daun selada sudah bertambah yakni menjadi 6 helai, dalam pembesaran nutrisi yang digunakan 600-800 PPM, sedangkan air bakunya 80-100 PPM (sebelum dicampur nutrisi (air sumur)). Tahap pembesaran merupakan tahap terakhir, hanya tinggal menunggu tahap panen sekitar satu bulan atau 40 hari paling lama. Biasanya selada dipanen pada hari ke-56 setelah semai(Warjoto et al., 2017).

\section{Tabel 2. Tabel Perkembangan Selada}

\begin{tabular}{|c|c|c|}
\hline Waktu & $\begin{array}{c}\text { Tinggi } \\
\text { Selada }\end{array}$ & $\begin{array}{c}\text { Banyaknya } \\
\text { Daun Selada }\end{array}$ \\
\hline $\begin{array}{c}\text { Minggu } \\
\text { pertama }\end{array}$ & $1,5-2 \mathrm{~cm}$ & 2 helai \\
\hline $\begin{array}{c}\text { Minggu } \\
\text { kedua }\end{array}$ & $2-2,5 \mathrm{~cm}$ & 3 helai \\
\hline $\begin{array}{c}\text { Minggu } \\
\text { ketiga }\end{array}$ & $4-5 \mathrm{~cm}$ & 6 helai \\
\hline $\begin{array}{c}\text { Minggu } \\
\text { keempat }\end{array}$ & $7-10 \mathrm{~cm}$ & $7-8$ helai \\
\hline $\begin{array}{c}\text { Minggu } \\
\text { kelima }\end{array}$ & $12-17 \mathrm{~cm}$ & $9-11$ helai \\
\hline
\end{tabular}

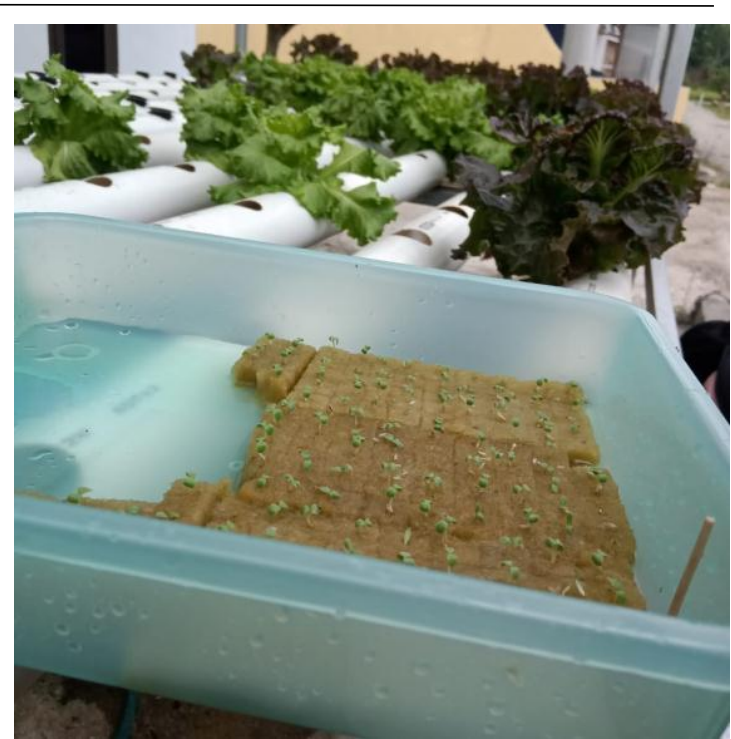

Gambar 1. Tampilan Gambar Selada Minggu Pertama

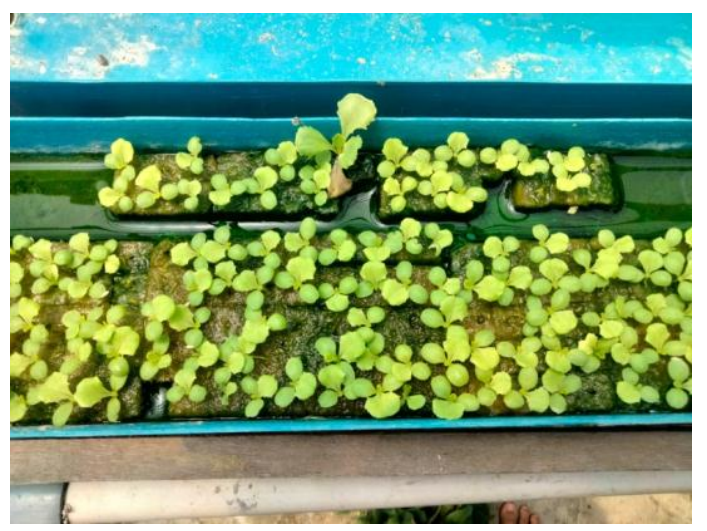

Gambar 2. Tampilan Gambar Selada Minggu Kedua

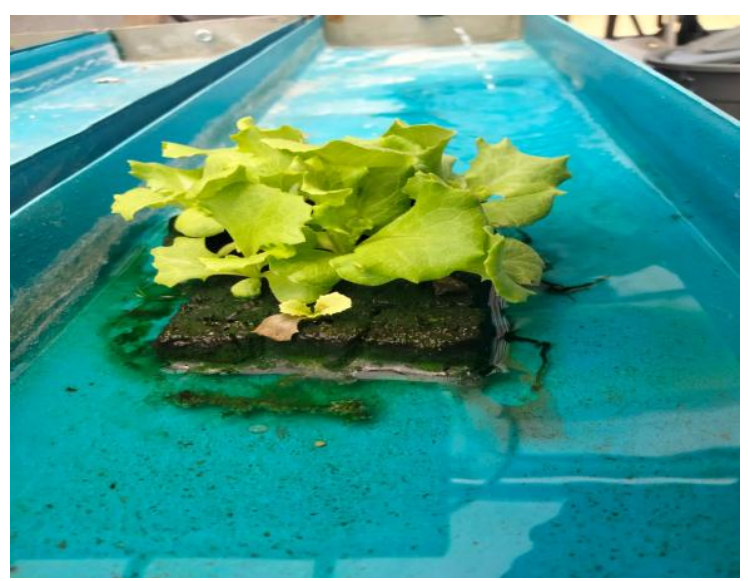

Gambar 3. Tampilan Gambar Selada Minggu Ketiga 


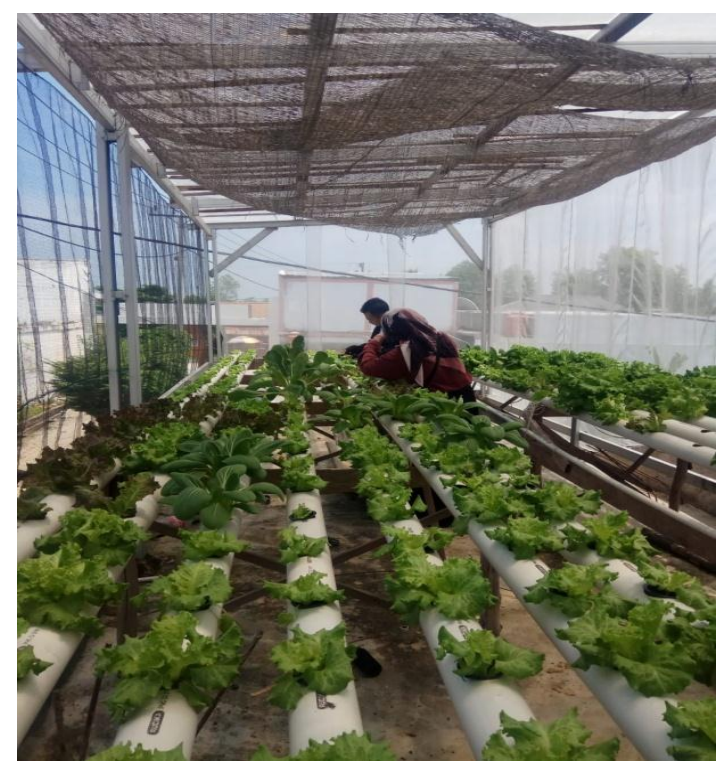

Gambar 4. Tampilan Gambar Selada Minggu Keempat

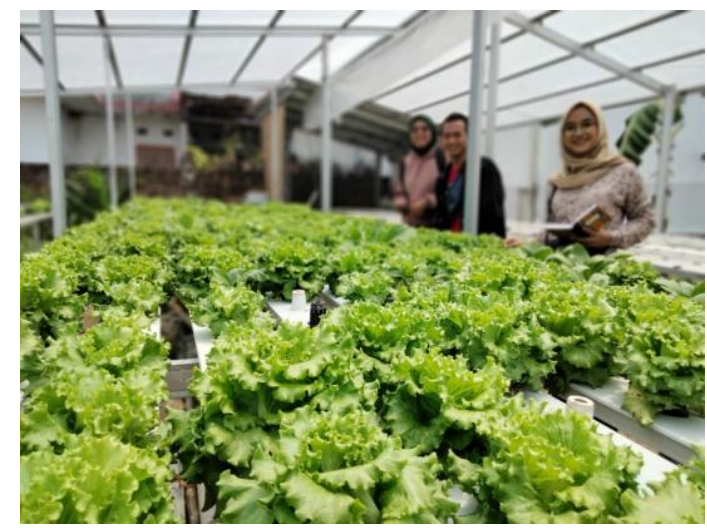

Gambar 5. Tampilan Gambar Selada Minggu Kelima

Temuan penelitian ini bahwa tumbuhan selada melalui proses tanaman hidroponik lebih higenis dan berkembang dengan baik, selain itu tanaman hidroponik dapat mengatasi sempitnya lahan yang dimiliki masyarakat. Namun, perlu ketelitian dan pengawasan lebih dalam agar tetap terjaga kualitas sayuran selada melalui tanaman hidroponik. Temuan penelitian di dukung oleh peneliti sebelumnya bahwa tanaman hidroponik memiliki kualitas yang lebih baik dan lahan yang lebih efektif dan efisien (Warjoto et al., 2020). Ada peneliti sebelumnya membuat rancangan media untuk penyiraman hidroponik (Kusumo \& Azis, 2021). Pada penelitian ini masih terbatas pada analisis satu tanaman yaitu selada. Penelitian berikutnya diharapkan untuk menganalisis berbagai tanaman sayur.

\section{Kesimpulan}

Hasil temuan pada penelitian ini bahwa menanam dengan cara hidroponik dapat mengatasi permasalahan akan sempitnya lahan yang dimiliki. Metode ini menjadi solusi bagi masyarakat. Tanaman hidroponik memiliki kualitas yang lebih baik dan lahan yang lebih efektif dan efisien. Penelitian ini fokus pada tanaman selederi.

\section{Ucapan Terima Kasih}

Penulis mengucapkan terima kasih kepada Saudara Jaya Herianto Simarmata karena telah mengizinkan penulis untuk melakukan observasi di lokasi hidroponik milik beliau, dan kami juga berterimakasih kepada Direktorat Jenderal Pendidikan Tinggi Kemendikbud Ristek melalui Program Inovasi Talenta Gelombang II Tahun 2021 yang telah memberikan dana artikel ini.

\section{Referensi}

Asri, A., Syam, N., \& Aminah. (2021). Pengaruh Berbagai Jenis Media Tanam dan Konsentrasi Nutrisi Larutan Hidroponik Terhadap Pertumbuhan dan Produksi Tanaman Mentimun Jepang (Cucumis sativus L.). Jurnal AgrotekMAS, 2(2), 7179.

Fajri, C., Susanto, Suworo, Sairin, \& Tarwijo. (2021). Pelatihan Perencanaan Kewirausahaan Hidroponik Dan Penguatan Kelembagaan Santripreneur Di Pesantren Al Wafi Islamic Boarding School Pengasinan Depok. Jurnal Pengabdian Kepada Masyarakat, 2(1), 154-160.

http://openjournal.unpam.ac.id/index.php/ JAL/article/view/8788/5618

Fatmawati, E. W., Agustin, F., \& Pratama, W. A. (2021). Kelayakan Usahatani Hidroponik Pakcoy Yang Dibudidayakan Dirumah Selama Pandemi COVID-19. Jurnal Agribest, 5(2), 72-77.

Haryanto, L. I., Putri, D. I., Naswandi, Sularno, Sukrianto, \& Rizqiya, F. (2021). 
Penerapan Budidaya Hidroponik dalam Kolaborasi Program Kelas Berkebun di Kecamatan Kebayoran Lama Kecamatan Kebayoran Lama. Seminar Nasional Pengabdian Masyarakat LPPM UMJ, 112.

Kusumo, B., \& Azis, N. (2021). Rancang Bangun Alat Penyiram Sayuran Hidroponik Menggunakan Arduino Mega 2560. Jurnal Media Informatika Budidarma, 5(1), 124-128. https://doi.org/10.30865/mib.v5i1.2584

Lathifah, N. N., Aziz, I. M. A., Himawan, D., \& Farokhah, L. (2021). Produktif Dirumah Dengan Menanam Hidroponik. Seminar Nasional Pengabdian Masyarakat LPPM UMJ, 1-6.

Masitah, M., Syahrir, S., Amin, M., \& Mandeva, P. (2021). Analisis Kelayakan Usahatani Selada Hidroponik Di Masa Pandemi Covid-19 Kabupaten Kolaka. Jurnal AGRISEP: Kajian Masalah Sosial Ekonomi Pertanian Dan Agribisnis, 20(2), 343-354.

https://doi.org/10.31186/jagrisep.20.2.343 $-354$

Paramita, W. N., \& Yuliani (2021). Efektivitas Pupuk Organik Cair dengan Penambahan Silika sebagai Media Tanam Hidroponik. Lentera Bio, 11(1), 36-43.

Primawati, S. N., Nissa, I. C., Nufida, B. A., Rizka, M. A., \& Febrilia, B. R. A. (2021). Pelatihan Hidroponik Sistem NFT bagi Kelompok Pertanian Patuh Angen di Kota Mataram. Jurnal Pengabdian UNDIKMA, 2(2), 243-251.

Ramady, G. D., Mahardika, A. G., Sujana, A., Abduh, M., \& Solehudin, M. (2021). Perancangan Model Prototipe Sistem Hidroponik Sebagai Media Pembelajaran Berbasis Mikrokontroler. Smart Comp, 10(3), 142-148.

Roidah, I. S. (2014). Pemanfaatan Lahan Dengan Menggunakan Sistem Hidroponik. Jurnal Universitas Tulungagung BONOROWO,

$$
\text { 1(2), 43-50. }
$$

Romalasari, A., \& Sobari, E. (2019). Produksi Selada (Lactuca sativa L.) Menggunakan Sistem Hidroponik Dengan Perbedaan Sumber Nutrisi. Agriprima: Journal of Applied Agricultural Sciences, 3(1), 3641.

https://doi.org/10.25047/agriprima.v3i1.1 58

Sanubary, I., Santoso, P. P. A., \& Mahmuda, D. (2021). Pembuatan Instalasi Panel Surya pada Sistem Hidroponik di Desa Dalam Kaum. Widyabhakti, 4(1), 31-35.

Warjoto, R. E., Barus, T., \& Mulyawan, J. (2020). Pengaruh Media Tanam Hidroponik terhadap Pertumbuhan Bayam (Amaranthus sp.) dan Selada (Lactuca sativa). Jurnal Penelitian Pertanian Terapan, 20(2), 118-125. https://doi.org/10.25181/jppt.v20i2.1610

Warjoto, R. E., Mulyawan, J., \& Barus, T. (2017). Pengaruh Media Tanam Hidroponik terhadap Pertumbuhan Bayam ( Amaranthus sp .) dan Selada ( Lactuca sativa) The Effect of Hydroponic Growing Media on Spinach (Amaranthus sp .) and Lettuce ( Lactuca sativa) Growth. 20(2), 118-125. 